\title{
THE ESTIMATION OF THE PROPORTION OF MOTILE BULL SPERMATOZOA IN VARIOUS DILUENTS AND A COMPARISON WITH THE PROPORTION EOSINOPHILIC
}

\author{
H. M. DOTT \\ A.R.C. Unit of Reproductive Physiology and Biochemistry, \\ Cambridge*
}

(Received 6th December 1974)

\begin{abstract}
Summary. The proportion of motile spermatozoa in bull semen diluted with phosphate-buffered saline, citrate or milk has been estimated both photographically and with an image-analysing computer. The two methods produced similar estimates. The proportion of noneosinophilic spermatozoa was higher than the proportion of immotile spermatozoa, particularly when fluoride or formaldehyde was added to the diluents. The proportion of non-eosinophilic spermatozoa in diluents containing formaldehyde was the same as in the original semen.
\end{abstract}

\section{INTRODUCTION}

Motility of spermatozoa is one of the most important parameters used in assessing the quality of semen, since this parameter is most closely correlated with the conception rate, at least in bull semen (Bishop, Campbell, Hancock \& Walton, 1954). Estimates of sperm motility are also used in experiments on metabolism of spermatozoa and in laboratory trials of diluents for semen in a variety of species. Usually, motility is assessed by visual examination and assigning a value based on an estimate of the proportion of motile spermatozoa and the vigour or movement as described by Emmens (1947).

The technique can be rapidly performed and does not require expensive equipment but in view of the importance attached to motility it is surprising that little use has been made of the more objective methods that have been described (e.g. Walton, 1952; Rothschild, 1948, 1953; Rikmenspoel, 1957; Harvey, 1945, 1960; Janick \& Macleod, 1970; van Duijn, van Voorst \& Freund, 1971).

It seemed likely that the image-analysing computer (Quantimet 720) could be used to estimate the proportion of motile spermatozoa in semen but a second method was required to confirm the results. A photographic method was used in conjunction with the Quantimet to estimate the proportion of motile spermatozoa in samples of bull semen in various diluents.

* Postal address: Animal Research Station, 307 Huntingdon Road, Cambridge CB3 0JQ. 
The proportion of spermatozoa stained by a differential stain has been correlated with the motility of bull semen (Bishop et al., 1954; Campbell, Hancock \& Shaw, 1960), but no direct comparison of the proportion stained with an objective determination of the proportion immotile has so far been undertaken with bull semen.

\section{MATERIALS AND METHODS}

\section{Semen}

Semen was collected in an artificial vagina from eight Friesian bulls on three separate occasions. The bulls were between 3 and 6 years old and were used in a progeny-testing scheme.

\section{Dilution}

The semen was diluted $1: 6$ or $1: 10$ so that the number of spermatozoa in a photograph would be about fifty.

\section{Diluents}

Three basic diluents were used: (1) a phosphate-buffered saline (PBS) solution containing $124 \mathrm{~mm}-\mathrm{NaCl} ; 6.8 \mathrm{~mm}-\mathrm{KCl} ; 3 \mathrm{~mm}-\mathrm{Na}_{2} \mathrm{HPO}_{4}$ and 0.7 mM- $\mathrm{NaH}_{2} \mathrm{PO}_{4}, \mathrm{pH} 7 \cdot 3$; (ii) a $2.9 \%$ citrate buffer, adjusted to $\mathrm{pH} 6.9$ with citric acid; and (iii) a milk diluent as described by Harrison \& White (1972) but with galactose replacing fructose. A portion of each ejaculate was diluted with each of the three diluents, and other portions were diluted with the basic diluents to which had been added $35.5 \mathrm{~mm}$-glucose or $10 \mathrm{~mm}-\mathrm{NaF}$ or $0.1 \%$ of $40 \%$ formaldehyde making a total of twelve samples from each ejaculate.

\section{Procedure}

Semen was collected from Bulls $A$ to $\mathrm{D}$ on one day and from Bulls $\mathrm{E}$ to $\mathrm{H}$ on another day. After the last collection on each day, the semen was brought into the laboratory. The twelve dilutions of the semen of the first bull were made and tested, and those of the second, third and fourth bulls were prepared as soon as possible thereafter, the same order being adopted on each occasion. Within bulls, the diluents were always tested in the same order: PBS, citrate, milk. Within diluents, the following order was adopted: no addition, glucose, sodium fluoride and formaldehyde. The test for each ejaculate took approximately $60 \mathrm{~min}$. Thus, semen from the last bull was kept in the laboratory for approximately $3 \mathrm{hr}$ before dilution.

The slide and coverslip were kept on the warm stage $\left(30^{\circ} \mathrm{C}\right)$ for $5 \mathrm{~min}$ before $5 \mu \mathrm{l}$ diluted semen was dropped onto the middle of the slide and the coverslip was allowed to settle on the drop; when the area under the coverslip was filled with semen, the depth of the chamber was approximately $10 \mu \mathrm{m}$. The slide was then put under the microscope and a suitable field selected by dark-ground illumination. Two minutes after the coverslip had been lowered, the field was photographed (2-sec exposures), the illumination was changed to phase contrast, and the image was directed through the Quantimet (Image Analysing Computers Ltd, IMANCO, Melbourn, Royston, Herts) which was adjusted to 
detect non-moving spermatozoa on one channel and all the spermatozoa on a second channel. Spermatozoa in the field were counted ten times and the results in both channels were noted. The illumination was changed back to dark ground and a second photograph was taken. There was an interval of 90 to $120 \mathrm{sec}$ between the first and second photographs. At the same time as the proportion of motile spermatozoa was being estimated, an eosin-nigrosin smear was prepared (Dott \& Foster, 1972) from another sample of the same dilution.

The change from dark-ground to phase-contrast illumination was facilitated by using the same condenser (NA 0.9 ) for both. Dark-ground illumination was obtained with a phase ring intended for a high-power objective as a patch stop for a $\times 10$ planachromatic objective. A $\times 10$ phase objective with a matched phase ring and a green filter was used for phase contrast. It was possible to photograph the field when it was illuminated by phase contrast and to obtain similar results if Kodalith film was used instead of the Ilford FP4 but the photographs were not so easy to count. Equally good results could be achieved with a simple Polaroid camera and dark-ground illumination since the exposure time when estimating only the proportion of motile spermatozoa was not critical to within $\frac{1}{2}$ sec.

\section{Estimation of the proportion of motile spermatozoa}

The calculation of the proportion of motile spermatozoa from the Quantimet figures involved calculating 1 -(No. immotile/Total number).

The photographs were printed to give a final magnification $\times 190$. Three groups of spermatozoa were distinguished and counted separately: (1) immotile spermatozoa, I; (2) motile spermatozoa whose tracks were entirely contained within the photographs, $\mathbf{T}_{1} ;(3)$ motile spermatozoa which had swum into or out of the field during the exposure, $\mathbf{T}_{2}$.

$$
\text { The proportion of motile spermatozoa }=1-\frac{I}{T_{1}+\frac{1}{2} \mathrm{~T}_{2}+\mathrm{I}}
$$

These figures were also used to obtain an estimate of the average velocity of the population from the formula $\overrightarrow{\mathrm{v}}=\frac{\pi}{2} \frac{\mathrm{N}}{\mathrm{Lt}_{\mathrm{F}} \overline{\mathbf{n}}}$ (Ojakian \& Katz, 1973), where $\mathrm{L}=$ the length of the perimeter of the photograph, $t_{F}=$ the time of exposure, $\bar{n}=$ the surface density, $N=$ the number of tracks entering or leaving the photograph.

\section{Statistical analysis}

The results were converted to angles before being subjected to analysis of variance and regression analysis.

\section{RESULTS}

\section{Effect of formaldehyde}

The Quantimet, the photographs, and direct observation all showed that none of the spermatozoa in diluents containing formaldehyde was motile and results from these diluents were omitted from the statistical analysis. 
Comparison of Quantimet, photograph and staining counts

The proportion of motile spermatozoa measured with the Quantimet $(0 \cdot 2884)$ was not significantly different from that obtained from photographs $(0.2661$; $r=0.844 ; P<0.001)$ but the proportion of unstained spermatozoa was significantly higher $(0.5634 ;$ S.E. of difference $=0.0137, P<0 \cdot 1)$.

The correlation coefficients between the proportion of motile spermatozoa and the log of the proportion of unstained spermatozoa are shown in Table 1. The correlation coefficients all had a $P<0.01$, and the coefficients with and without glucose did not differ significantly from each other either for the Quantimet $(t=0.978)$ or for photographic $(t=0.565)$ counts. On three occasions, samples diluted in the basic diluent with and without glucose were tested a second time $2 \mathrm{hr}$ after the first. The proportions of motile spermatozoa were 0.321 (first test) and 0.341 (second test). These do not differ significantly (S.E. of difference $=0.058$ ).

Table 1. Correlation coefficients between the proportion of motile spermatozoa and log of proportion of unstained spermatozoa exposed to eosin-nigrosin

\begin{tabular}{llll}
\hline $\begin{array}{c}\text { Proportion of } \\
\text { of motile } \\
\text { spermatozoa } \\
\text { estimated by: }\end{array}$ & Basic & $\begin{array}{c}\text { Basic with } \\
\text { glucose }\end{array}$ & $\begin{array}{c}\text { Basic with } \\
\text { and without } \\
\text { glucose }\end{array}$ \\
\cline { 2 - 4 } & & $0.379^{*}$ & $\begin{array}{l}0.446 \\
0.498\end{array}$ \\
\hline Quantimet & 0.512 & 0.464 & \\
\hline
\end{tabular}

$* 0.1>P>0.01 ; P$ for all others $<0.01$.

Decrease in the proportion of motile spermatozoa during observations

The first photograph was always taken $2 \mathrm{~min}$, and the second $3 \frac{1}{2}$ to $4 \mathrm{~min}$, after the preparation of the slide.

When there was no addition to the diluent, the ratio of the proportion immotile after the Quantimet count to the proportion immotile before the Quantimet count was $1 \cdot 15$. When glucose was present, there was a smaller mean increase, i.e. 1.07, and when $\mathrm{NaF}$ was added, there was no increase, i.e. 0.99 $(F=14.15$ on 2 , 144 d.f., $P<0.01$; S.E. of difference $=0.022)$.

The over-all mean increase was 1.07 . Two of the eight bulls were consistently higher than this $(1.14$ and 1.12$)$ and one did not exhibit any increase in the proportion immotile, i.e. 0.97 ( $F=3.024$ on 7,144 d.f., $0.1>P>0.01$; S.E. of difference $=0.036$ ). None of the interactions was significant.

In 141 samples which contained motile spermatozoa, spermatozoa in seventyone had an estimated velocity of 1 to $24.99 \mu \mathrm{m} / \mathrm{sec}$; those in thirty-two, between 25 and $49.99 \mu \mathrm{m} / \mathrm{sec}$; those in twenty-six, between 50 and 79.99 , and those in twelve $>80$. The mean proportion of immotile spermatozoa increased more in the faster group than in the slower group (1.28 and 1.06, $t=2.77,12$ d.f., $0.05>P>0.02$ ). 


\section{Effect of fluoride}

There were fewer motile spermatozoa in the diluents containing fluoride than in the others (Tables 2 and 3), except when citrate was used as the basic diluent (Table 3 ). The proportion of unstained spermatozoa was the same in all diluents (Table 2).

Table 2. The proportion of motile and unstained spermatozoa in basic diluents with and without glucose and with sodium fluoride

\begin{tabular}{lccc}
\hline \multirow{2}{*}{ Diluent } & \multicolumn{3}{c}{ Method of estimation } \\
\cline { 2 - 4 } & Quantimet & Photograph & Stain \\
\hline Without glucose & 0.415 & 0.412 & 0.569 \\
With glucose & 0.314 & 0.299 & 0.536 \\
With sodium fluoride & 0.136 & 0.087 & 0.586 \\
\hline
\end{tabular}

Standard error of difference $=0.024$

Table 3. The proportion of motile spermatozoa in different diluents

\begin{tabular}{lccc}
\hline & \multicolumn{3}{c}{ Basic diluent } \\
\cline { 2 - 4 } \multicolumn{1}{c}{ Additive } & $\begin{array}{c}\text { Phosphate- } \\
\text { buffered } \\
\text { saline }\end{array}$ & Citrate & Milk \\
& 0.4306 & 0.4075 & 0.4032 \\
None & 0.3862 & 0.2928 & 0.3401 \\
With glucose & 0.0689 & 0.2326 & 0.0329 \\
With sodium fluoride & 0689 & & \\
\hline
\end{tabular}

Standard error of difference $=0.041$.

Table 4. Proportion of unstained spermatozoa* in different diluents

\begin{tabular}{lcll}
\hline & \multicolumn{3}{c}{ Basic diluent } \\
\cline { 2 - 4 } \multicolumn{1}{c}{ Additive } & $\begin{array}{c}\text { Phosphate- } \\
\text { buffered } \\
\text { saline }\end{array}$ & Citrate & Milk \\
\hline None & 0.5309 & 0.5344 & 0.6263 \\
With glucose & 0.5109 & 0.5319 & 0.6013 \\
With sodium fluoride & 0.5216 & 0.5147 & 0.6134 \\
With formaldehyde & 0.7009 & 0.6672 & 0.7122 \\
\hline
\end{tabular}

Standard error of difference $=0.03$.

$* 0.73$ in undiluted semen.

Nigrosin-eosin staining and formaldehyde

An analysis of variance was performed on the proportion of spermatozoa unstained in all treatments and in the original undiluted semen. The mean 


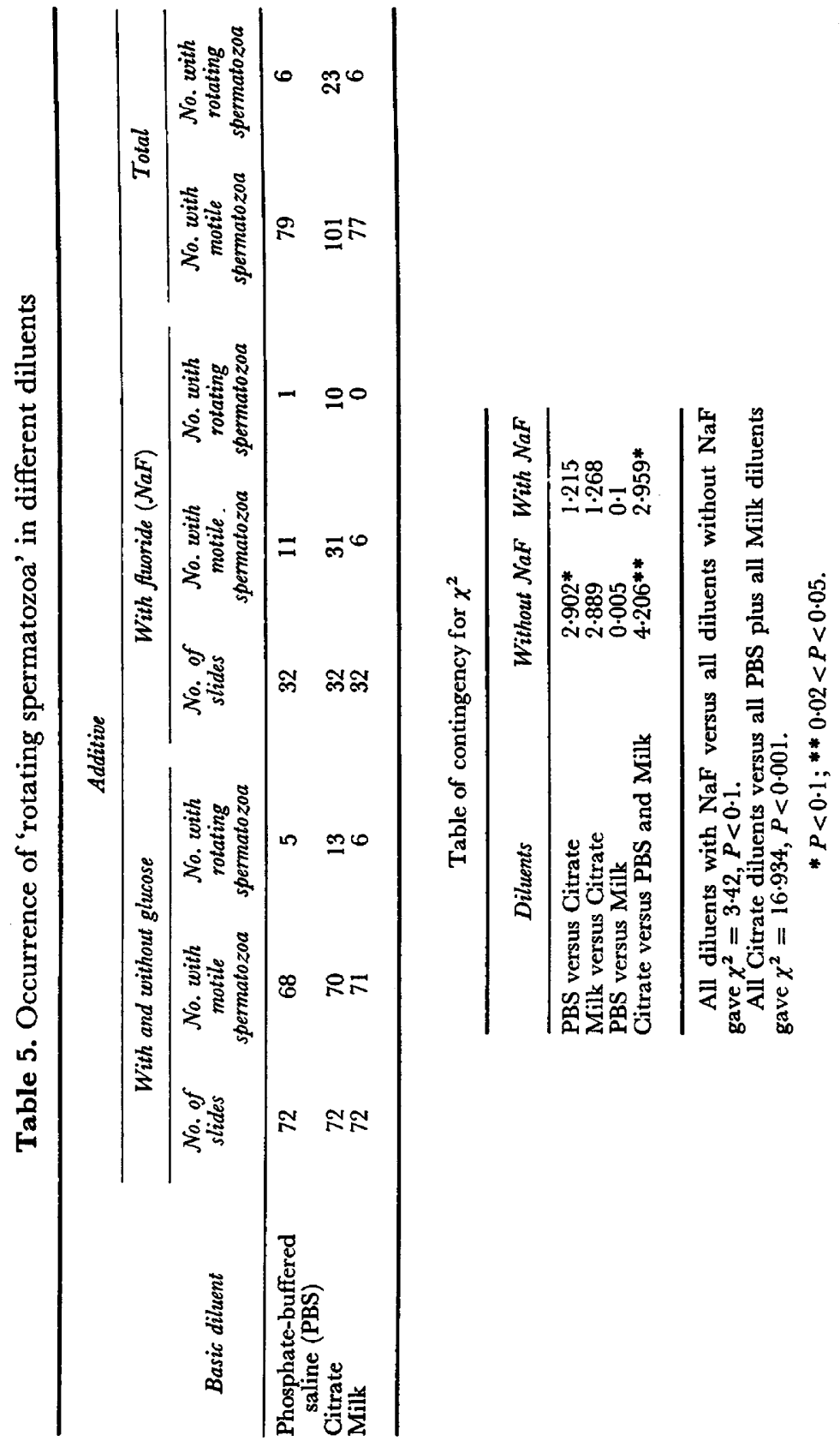


proportion unstained in the original semen was greater than in any of the diluents unless formaldehyde had been added to the diluent (Table 4).

\section{Quality of motility}

During the course of preliminary experiments, it had been observed that on some occasions the sperm tails appeared to move in two planes and sometimes in three planes with rotation of the head. Throughout the main series of experiments, if any spermatozoa on a slide were observed to rotate this was noted. The frequency of occurrence of slides with motile spermatozoa on which rotating spermatozoa were observed is given in Table 5. Rotating spermatozoa were seen more often in the citrate diluent than in PBS and milk $\left(\chi^{2}=16.934\right.$ on 1 d.f., $P<0.001$ ).

\section{DISCUSSION}

It has been shown that the proportion of motile spermatozoa in a population can be calculated rapidly and accurately with the Quantimet by comparing the calculations with those obtained from the same fields by a photographic method. The Quantimet count has two advantages over the photographic method, it is quicker and more spermatozoa can be counted in each field without loss of accuracy. This means that a more reliable estimate of the proportion of motile spermatozoa in a sample of semen can be obtained because more fields can be counted and the fields do not have to be selected on the basis of the number of spermatozoa they contain, provided a suitable dilution rate is employed.

Campbell et al. (1960) obtained a good correlation $(r=0.834)$ between the proportion of non-eosinophilic spermatozoa and a subjective estimate of motility which probably contained a factor associated with the velocity of the spermatozoa. The correlation between the proportion of motile spermatozoa and the proportion which are non-eosinophilic is lower and is not linear (Table 1). The low correlation may be due in part to the selection of fields for estimates of motility, but the non-linearity probably results from the fact that the affinity of spermatozoa for eosin and their ability to move are affected in different ways by the same treatment. For example, the motility of spermatozoa is inhibited by formaldehyde and by fluoride (Table 3) but their affinity for eosin is unaffected (Table 4; also Buttle, Hancock \& Purser, 1965). Some samples of seminal plasma may affect motility of spermatozoa more than their affinity for eosin. In this experiment, there was no significant bull interaction but three of the bulls had a significantly different rate of decrease in the proportion of motile spermatozoa during incubation than the other five.

The maintenance of the proportion of motile spermatozoa in diluted samples of semen held in test tubes at room temperature for $2 \mathrm{hr}$ is in sharp contrast to the decrease in the proportion of motile spermatozoa in approximately $1 \frac{1}{2}$ min when they were on a slide at $30^{\circ} \mathrm{C}$. This decrease was most marked when no external substrate was supplied and there was no change during the period of incubation when $\mathrm{NaF}$ was present. There was also a greater decrease in the proportion of motile spermatozoa during incubation in samples in which the 
spermatozoa had a high mean velocity. All these suggest that the loss of motility is due to exhaustion of substrates and, since it affects only some of the population, the substrate that is being exhausted is presumably endogenous. The inhibition of motility by exhaustion of substrate or by $\mathrm{NaF}$ can be reversed (Mann \& Lutwak Mann, 1948; Dott, 1958). It is possible that some of the immotile non-eosinophilic spermatozoa in unincubated samples could be stimulated to move by suitable treatment.

The behaviour of spermatozoa in the PBS and milk diluents differed from their behaviour in citrate in two ways; first, the motility of spermatozoa in PBS and milk was almost completely inhibited by fluoride whereas the motility in citrate was unaffected. This was probably due to the interaction of citrate and electrolytes in the semen. The second difference was in the type of motility exhibited by the spermatozoa; they were more likely to exhibit the rotating motility which Rikmenspoel (1957) described as normal when they were in citrate than in PBS or milk (Rikmenspoel only used a diluent containing citrate in his studies). It will be interesting to find out if the spermatozoa in PBS and milk have a different mean velocity from those in citrate. An experiment with the Quantimet to determine velocity (D. Katz and H. M. Dott, unpublished) is in progress.

The proportion of eosinophilic spermatozoa in the original semen did not differ from that in samples diluted with diluents containing formaldehyde and was lower than in the other diluents. The preservation of the status quo in respect of eosinophilia by formaldehyde has been investigated further and forms the subject of a separate communication (Dott \& Foster, 1975).

\section{ACKNOWLEDGMENTS}

I should like to thank Mr D. E. Walters, A.R.G. Statistics Unit, for advice on the statistics and Mr G. C. Foster for assistance in the laboratory.

\section{REFERENCES}

Bishop, M. W. H., Campbeli, R. C., Hancock, J. \& Wazton, A. (1954) Semen characteristics of fertility in the bull. F. agric. Sci., Camb. 44, 227-248.

Buttle, H. R. L., Hancock, J. \& Purser, A. F. (1965) Counting dead spermatozoa in frozen semen. Anim. Prod. 7, 59-65.

Campbelt, R. G., Hancock, J. \& Shaw, J. G. (1960) Cytological characteristics and fertilizing capacity of bull spermatozoa. J. agric. Sci., Camb. 55, 91-99.

Dotт, H. M. (1958) Species differences in the metabolism of epididymal spermatozoa. Stud. Fert. 10, 73-79.

Dotr, H. M. \& Foster, G. G. (1972) A technique for studying the morphology of mammalian spermatozoa which are eosinophilic in a differential live/dead stain. F. Reprod. Fert. 29, 443-445.

DotT, H. M. \& Foster, G. C. (1975) Preservation of differential staining of spermatozoa by formol citrate. 7. Reprod. Fert. 45, 57-60.

Emmens, C. W. (1947) The motility and velocity of rabbit spermatozoa at different hydrogen-ion concentration. F. Physiol., Lond. 106, 471-481.

Harrison, R. A. P. \& WhITE, I. G. (1972) Some methods for washing spermatozoa from bull, boar and ram; a comparison using biochemical and other criteria. F. Reprod. Fert. 29, 271-284.

HARveY, C. (1945) A method of estimating the activity of spermatozoa. Nature, Lond. 155, 368.

HARVEY, G. (1960) The speed of human spermatozoa and the effect on it of various diluents, with some preliminary observation on clinical material. 7. Reprod. Fert. 1, 84-95.

JANick, J. \& MACLEOD, J. (1970) The measurement of human sperm motility. Fert. Steril. 21, 140-146. 
Mann, T. R. R. \& Lutwak ManN, C. (1948) Studies on the metabolism of semen. 4. Aerobic and anaerobic utilization of fructose by spermatozoa and seminal vesicles. Biochem. F.43, 266-270.

Ojakian, G. K. \& Katz, D. F. (1973) A simple technique for the measurement of swimming speed of Chlamydomonas. Expl Cell Res. 81, 487-491.

Rikmenspoes, R. (1957) Photoelectric and cinematographic measurements of the motility of bull sperm cells. Thesis, University of Utrecht, Netherlands.

Rothschild, LORD (1948) The activity of ram spermatozoa. F. exp. Biol. 25, 219-226.

Rothschild, LORD (1953) A new method of measuring the activity of spermatozoa. J. exp. Biol. 30, 178-199.

van Duijn, C., JR, van Voorst, G. \& Freund, M. (1971) Movement characteristics of human spermatozoa analysed from kine-micrographs. Eur. F. Obstet. Gynec. 4, 121-135.

Walton, A. (1952) Flow orientation as a possible explanation of 'wave motion' and 'rheotoxis' of spermatozoa. F. exp. Biol. 29, 520-531. 